\title{
LOS CONSEJOS DE JUSTICIA EN EL ACTUAL PROCESO DE REFORMAS ESTATUTARIAS Y SUS PERSPECTIVAS DE FUTURO
}

MIGUEL ÁNGEL CABELLOS ESPIÉRREZ 
SUMARIO

1. LA APROXIMACIÓN DEL GOBIERNO DEL PODER JUDICIAL A LA ESTRUCTURA COMPUESTA DEL ESTADO Y LAS ACTUALES REFORMAS ESTATUTARIAS. 1.1. Precedentes. 1.2. El actual proceso de reformas estatutarias y la diversidad de modelos. 2. EL CONSEJO DE JUSTICIA CONTENIDO EN EL ESTATUTO DE AUTONOMÍA DE CATALUÑA Y SU ENJUICIAMIENTO POR EL TRIBUNAL CONSTITUCIONAL. 2.1. Premisa: la posibilidad de colaboración internormativa entre el Estatuto y la LOPJ. 2.2. La colaboración internormativa en el ámbito de la justicia en la sentencia sobre el Estatuto catalán. 2.3. Elementos del examen por parte del TC del Consejo de Justicia. 2.3.1. La exclusión de la colaboración internormativa. 2.3.2. La confusión sobre la naturaleza del órgano. 2.3.3. La distinción entre atribuciones y la reinvención del órgano. 2.4. Escenarios tras la sentencia. 


\title{
LOS CONSEJOS DE JUSTICIA EN EL ACTUAL PROCESO DE REFORMAS ESTATUTARIAS Y SUS PERSPECTIVAS DE FUTURO ${ }^{1}$
}

\author{
POR \\ MIGUEL ÁNGEL CABELLOS ESPIÉRREZ \\ Profesor titular de Derecho Constitucional. \\ Universidad de Girona
}

\section{LA APROXIMACIÓN DEL GOBIERNO DEL PODER JUDICIAL A LA ESTRUCTURA COMPUESTA DEL ESTADO Y LAS ACTUALES REFORMAS ESTATUTARIAS}

\subsection{Precedentes}

La atribución por la Constitución de la función de gobierno del Poder Judicial al CGPJ no ha impedido que la doctrina haya debatido sobre cómo la misma pudiera desempeñarse de modo más cercano al territorio y a los jueces y magistrados destinatarios de sus decisiones ${ }^{2}$. Y no sólo los autores, sino las propias instituciones,

${ }^{1}$ Este trabajo se integra en el proyecto de investigación financiado por el Ministerio de Ciencia e Innovación con referencia DER2010-15778, sobre «Los cambios en la relación entre Poder Judicial y Comunidades Autonómas: perspectivas de interpretación a la luz del Derecho comparado». Asimismo, durante la elaboración del mismo tuve oportunidad de debatirlo con los profesores Miguel Ángel Aparicio, Manuel Gerpe y Carles Viver, a quienes deseo agradecer sus comentarios y sugerencias.

${ }^{2}$ Vd., entre otros, Xiol Ríos, J.A., «La incidencia del Estado autonómico sobre la Administración de Justicia», en Informe Pi i Sunyer sobre Comunidades Autónomas, 1994. Fundació Pi i Sunyer d'estudis autonòmics i locals, Barcelona, 1995; del mismo autor: «Evaluación de los aspectos 
han valorado de qué modo podría conseguirse este fin dentro del marco constitucionalmente previsto.

En tal sentido, el Libro Blanco del CGPJ en 1997 propugnaba que se reforzasen las funciones de las Salas de Gobierno de los TSJ, en tanto que órgano superior de dirección de la Administración de Justicia en la Comunidad Autónoma. Una de las vías de dicho refuerzo serían, indicaba el propio Libro, las delegaciones que les hiciera el CGPJ en materias de gobierno interno ${ }^{3}$. El CGPJ se mantendría como órgano superior de gobierno, y por debajo de él las Salas de Gobierno actuarían como «auténticos órganos generales del gobierno interno del Poder Judicial en el respectivo territorio», consiguiéndose de este modo «un reflejo de la configuración territorial del Estado en lo que atañe al gobierno del Poder Judicial» ${ }^{4}$.

El propio CGPJ, en un informe sobre la situación de la Administración de Justicia hecho público en el año 2000, volvió a referirse al tema, si bien es cierto que la incidencia que sobre el mismo se hizo en su versión inicial no se plasmó apenas en la versión final ${ }^{5}$. La versión inicial proponía modificar la composición

relacionados con la Administración de Justicia en una futura reforma del Estatuto de Autonomía de Cataluña», en VVAA, Estudios sobre la reforma del Estatuto, IEA, 2004; López Guerra, L., «La adaptación del Consejo General del Poder Judicial a la estructura compuesta del Estado», en VVAA, La justícia a Catalunya en el marc d'un Estat compost, IEA/Generalitat de Catalunya, Barcelona, 2000; y en la misma obra colectiva: Albertí Rovira, E., «La adaptación del Consejo General del Poder Judicial a la estructura compuesta del Estado». Por su parte, Lucas Murillo de la Cueva ha llamado la atención sobre el «carácter tardío de la mirada autonómica sobre el Poder Judicial (...). Parece que solamente cuando se ha consolidado el ordenamiento autonómico es cuando surge con fuerza la preocupación por la adaptación abordada en los nuevos Estatutos». Vd. Lucas Murillo de la Cueva, P., «El Poder Judicial en Andalucía y las competencias autonómicas en materia de justicia», en Muñoz Machado, S., y Rebollo Puig, M., dirs. Comentarios al Estatuto de Autonomía para Andalucía, Thomson-Civitas, 2008, págs. 954-955.

${ }^{3}$ Vd. Libro Blanco de la Justicia, CGPJ, 1997, pág.323.

${ }^{4}$ Vd. Libro Blanco..., ob.cit., pág.324. En esta misma línea de vincular gobierno y territorio, se sugería que los órganos territoriales de gobierno del Poder Judicial y las autoridades autonómicas competentes cooperasen en asuntos de interés común a través de comisiones mixtas.

${ }^{5}$ El Pleno del CGPJ, en su reunión de 25 de septiembre de 1999, acordó dirigirse a las Salas de Gobierno de los TSJ, de la Audiencia Nacional y del TS, para que le hiciesen propuestas de reformas legislativas tendentes a mejorar la situación de la Administración de Justicia. Al mismo tiempo, constituyó una comisión compuesta por vocales del Consejo (por acuerdo del Pleno de 14 de octubre) que sobre esas propuestas y sobre el Libro Blanco de 1997 redactase un informe que se enviaría al Gobierno y a las Cortes. El Informe fue redactado en su versión inicial por dicha comisión, y recibió enmiendas de otros vocales. El informe y las enmiendas fueron debatidas en tres sesiones del Pleno del CGPJ (18, 19 y 25 de julio de 2000) y tras ello se adoptó el texto definitivo, sensiblemente distinto al inicial especialmente en lo que se refiere a los mecanismos de aproximación del Poder Judicial al modelo de Estado. Véase sobre ello Cabellos Espiérrez, M.A., «La adecuación del Poder Judicial al modelo de Estado», Revista Vasca de Administración Pública, 68, 2004, págs. 77-124. 
de las Salas de Gobierno de los TSJ ${ }^{6}$, y en sus apartados 40 y 41 enunciaba las funciones que, previa reforma de la LOPJ, debieran atribuírseles: nombramiento de presidentes de Audiencias, Magistrados suplentes y jueces sustitutos; funciones de inspección; presentación de la Memoria Anual por el Presidente ante el parlamento autonómico; formación continua y, por último, concesión de compatibilidades, licencias y permisos ordinarios. El informe final, no obstante, no recogió finalmente estas propuestas.

La idea central del Libro Blanco y del Informe inicial (que no del final) de 2000 era, pues, potenciar las facultades de gobierno de las Salas de Gobierno de los TSJ, lo que debiera favorecer tanto la descarga de trabajo del CGPJ como, por otra parte, la aproximación del gobierno de los órganos del Poder Judicial a estos y a los territorios en que los mismos operan ${ }^{7}$. El Pacto de Estado para la reforma de la justicia se hizo eco de ello en su apartado tercero a través de una mención genérica a que «se aumentarán, precisándolas con detalle, las competencias de las Salas de Gobierno de los Tribunales Superiores de Justicia y se establecerán mecanismos de delegación de funciones, singularmente en materia inspectora y disciplinaria», lo que no tuvo ningún reflejo destacable en la L.O.19/2003, de reforma de la LOPJ.

\subsection{El actual proceso de reformas estatutarias y la diversidad de modelos}

Así las cosas, en el proceso de reformas estatutarias que ha comenzado a hacerse realidad con la aprobación de las primeras reformas en 2006, el problema de la aproximación del Poder Judicial al modelo de Estado se ha hecho, lógicamente, presente. Los diversos estatutos hasta ahora reformados han incorporado

\footnotetext{
${ }^{6}$ Según la propuesta, pasarían a estar formadas por el presidente del TSJ, los presidentes de las Audiencias Provinciales (hasta un máximo de 4 y con posibilidad de rotación en caso de ser un número mayor), igual número de magistrados y jueces elegidos mediante sistema proporcional, jueces decanos exentos de tareas jurisdiccionales y un tercio de juristas, elegidos por mayoría de $3 / 5$ por los Parlamentos autonómicos.

${ }^{7}$ No se acogía, pues, la posibilidad de la desconcentración en órganos internos del propio CGPJ. En torno a ello se mostraba crítico Vidal Andreu, para quien «la potenciación de las Salas de Gobierno, como órganos de gobierno interno de los tribunales, ha demostrado su ineficacia a lo largo de los años. Dejar el gobierno de los jueces en manos única y exclusivamente de ellos mismos no parece que sea la mejor de las soluciones, tizna de corporativismo su imagen, desconoce el diseño autonómico constitucional y margina la trascendencia de unas competencias transferidas en materia de medios materiales y de recursos humanos». Vd. su respuesta a la encuesta del libro $L a$ justicia ante la reforma de los Estatutos de Autonomía, CEJ-Thomson-Aranzadi, 2005, págs. 120-121.
} 
previsiones tendentes a abordar esta cuestión, de las que ahora nos interesan las relativas a los consejos de justicia, objeto, por lo que al estatuto catalán se refiere, de análisis por parte del Tribunal Constitucional en su reciente sentencia $31 / 2010$, de 28 de junio, con la consecuencia ya conocida de la declaración de inconstitucionalidad de buena parte de los preceptos alusivos a dicho consejo.

Si en los documentos institucionales y en la propia doctrina había predominado la línea tendente a aumentar las competencias de las Salas de Gobierno de los TSJ, ha sido la opción por los consejos de justicia la que se ha plasmado en los nuevos Estatutos ${ }^{8}$. Pero debe ponerse de manifiesto de inmediato que los Estatutos reformados no contienen un modelo único u homogéneo de consejo de justicia sino, por el contrario, dos modelos absolutamente distintos en su naturaleza, y ello hasta el punto de que puede afirmarse que uno de los dos, en realidad, nada tiene que ver con el gobierno del Poder Judicial y con su aproximación al modelo de Estado, advertencia ésta que, como se verá, deberá ser muy tenida en cuenta al examinar el contenido y efectos de la sentencia 31/2010 sobre los consejos de justicia.

En efecto: el Estatuto catalán y el andaluz apuestan por la existencia de un Consejo de Justicia configurado no como un órgano de la Comunidad, sino como un órgano desconcentrado del CGPJ 9 .

${ }^{8}$ Opción que se quiso llevar también a la LOPJ. Como es sabido, durante la VIII Legislatura estuvo en tramitación en las Cortes un Proyecto de Ley Orgánica de modificación de la Ley 6/1985, de 1 de julio, del Poder Judicial, en materia de justicia de proximidad y Consejos de Justicia. Fue presentado en el Congreso el 29 de diciembre de 2005 y, tras 71 (sic) ampliaciones del plazo de enmiendas, fue conducido a su caducidad al disolverse las Cortes en enero de 2008. El proyecto tenía (entre otras cosas) como objeto introducir en la LOPJ la regulación de los citados Consejos, y para ello preveía su composición, la participación de los parlamentos autonómicos en la elección de una parte de ellos (juristas de reconocido prestigio), los órganos de cada Consejo, sus reglas de funcionamiento, vías para recurrir sus actos, etc. Es de suponer que, una vez dictada la sentencia sobre el Estatuto catalán y conocidos los términos en que ésta se pronuncia sobre el Consejo de Justicia y sobre la posibilidad de que la LOPJ pueda acoger este tipo de órganos, se reactive la reforma de dicha norma en este ámbito durante la actual legislatura.

${ }^{9}$ Ciertamente esta opinión no es unánime: la regulación relativa a la Administración de Justicia contenida en la propuesta de Estatuto catalán fue objeto de un «Estudio» emitido por el CGPJ el 25 de enero de 2006, donde éste argumenta la, a su juicio, inconstitucionalidad de buena parte de la misma. Luego de intentar justificar su discutida y discutible competencia para emitir el mencionado estudio, el CGPJ analiza la regulación proyectada y, por lo que se refiere al Consejo de Justicia, concluye que «de la forma de composición del Consejo, del análisis de las competencias que se le atribuyen más de su régimen de vinculación al CGPJ, se desprende la configuración de un órgano gubernativo judicial claramente inserto en el sistema institucional de la Generalidad, luego como parte de la forma política de organización del autogobierno de Cataluña por emplear los términos del artículo 2.1. No es expresamente un órgano de gobierno de la Ge- 
Tal carácter se reconoce expresamente en el caso del Consejo catalán, «(...) órgano de gobierno del poder judicial en Cataluña» que «actúa como órgano desconcentrado del Consejo General del Poder Judicial (...)» (art. 97). En el caso del andaluz, su artículo 144.1 no menciona expresamente el carácter de órgano desconcentrado del CGPJ que tendría el Consejo de Justicia, pero el mismo se deriva necesariamente de la configuración que el Estatuto hace de dicho Consejo: definido por el mencionado precepto como «órgano de gobierno de la Administración de Justicia en Andalucía», ni la omisión a la naturaleza de órgano desconcentrado ni el cambio de la mención al Poder Judicial por la relativa a la Administración de Justicia han de llevar a engaño: dotado el Consejo de las mismas funciones y composición que el catalán y diseñado en definitiva casi de modo idéntico a éste, se sigue de todo ello la consecuencia lógica de su carácter de órgano desconcentrado del CGPJ, pues un organismo autonómico no podría en ningún caso desempeñar las funciones que el Estatuto andaluz prevé (siempre previa mediación de la LOPJ) para dicho Consejo y que el art.144.1 EAAnd, como el 98.2 EAC, conceptúan claramente como «atribuciones del Consejo de Justicia de Andalucía respecto a los órganos jurisdiccionales situados en su territorio». No hay, pues, una limitación del alcance de las funciones del órgano al ámbito de las competencias de la Comunidad en materia de Administración de Justicia, sino que claramente se va más allá de esto para pasar al ámbito propio del gobierno de los órganos jurisdiccionales.

$\mathrm{Y}$ es igualmente relevante hacer notar que ninguno de los dos estatutos mencionados dicen que el Consejo se creará por ley autonómica, sino que se sobreentiende que, teniendo como tendrá funciones que incidirán en el gobierno del Poder Judicial, y perteneciendo como pertenecerá al CGPJ, sólo la LOPJ podrá crearlo. Por ello, finalmente, sus funciones serán, aparte de las que le atribuya el Estatuto — con la mediación de la propia LOPJ— las restantes que le confiera ésta u otras leyes autonómicas y (por pura lógica teniendo en cuenta su carácter de órgano desconcentrado del CGPJ) las que éste le delegue (vd. arts. 98.1 EAC y 144.3 EAAnd).

neralidad, pero la regulación analizada produce el efecto equivalente. En definitiva, el sistema de gobierno que alumbra la Propuesta de Reforma del Estatuto catalán se asemeja a una suerte de usufructo institucional. El Estado sería el nudo propietario del Consejo cuyo uso y explotación habría cedido a la Comunidad catalana, poseedora directa y beneficiaria de los frutos políticos de tal explotación: la generación material o real de su propio Poder Judicial» (pág. 38). En las páginas 45 a 47 se abunda en esta y otras causas de inconstitucionalidad que, en opinión del Consejo, concurrirían, y cuya exposición por parte de éste nos sitúa más en el terreno del juicio de intenciones que en el del análisis normativo. 
El resto de Estatutos, en cambio, prevén algo muy diferente: un consejo asesor de la Comunidad en materia de justicia, para aquellos ámbitos en que la Comunidad tenga competencia. Pertenecerá, pues, a la Comunidad, nada tendrá que ver con el CGPJ ni con el gobierno del Poder Judicial (y sí, cabe insistir, con aquellas cuestiones sobre las que sí se proyecte la competencia autonómica en el ámbito de la justicia, que ya sabemos que no alcanzan al gobierno del Poder Judicial), y por ello podrá ser creado por ley autonómica. Véase por ejemplo el art. 33.3 del Estatuto valenciano tras su reforma por L.O 1/2006:

«Se crea el Consell de la Justicia de la Comunitat Valenciana. Una Ley de Les Corts determinará su estructura, composición, nombramientos y funciones dentro del ámbito de las competencias de la Generalitat en materia de administración de justicia en los términos que establece el presente Estatuto y de acuerdo con lo dispuesto en la Ley Orgánica del Poder Judicial».

El Estatuto es claro al determinar las competencias del Consejo: éstas se proyectan sobre el ámbito de las competencias de la Comunidad en materia de Administración de Justicia, lo que apunta lógicamente al ámbito de la administración de la Administración de Justicia, en los términos que establezca la LOPJ. El Consejo de Justicia, por tanto, no tiene como fin incidir en el gobierno del Poder Judicial ${ }^{10}$. Y en coherencia con todo lo anterior, puede lógicamente ser creado por ley autonómica, ya que se trata de un consejo asesor de la comunidad y no de un órgano desconcentrado del CGPJ, que naturalmente una ley autonómica nunca podría crear.

Lo mismo pasa con el resto de Estatutos, que siguen este modelo de consejo asesor de la Comunidad, que creará una ley autonómica y cuyas competencias de asesoramiento a la Comunidad se proyectan sobre las competencias de ésta en el ámbito de la administración de la Administración de Justicia ${ }^{11}$.

${ }^{10}$ Tanto es así que el art. 33.4 da por hecho que la Sala de Gobierno del TSJ seguirá teniendo su actual papel, pues en ningún caso se pretende que el Consejo tome las funciones que hasta ahora desempeñaba ésta en relación con el gobierno de los órganos jurisdiccionales. Y por ello el mencionado precepto prevé que «La colaboración entre la Sala de Gobierno del Tribunal Superior de Justicia de la Comunitat Valenciana y la Conselleria competente en materia de Justicia será a través de la Comisión Mixta».

${ }^{11}$ Art. 96 del Estatuto de las Islas Baleares: «Se crea el Consejo de Justicia de las Illes Balears. Una ley del Parlamento de las Illes Balears determinará su estructura, composición, nombramientos y funciones en el ámbito de las competencias de las Illes Balears en materia de administración de justicia en los términos que establece este Estatuto y de acuerdo con lo que dispone la Ley Orgánica del Poder Judicial. Los miembros del Consejo de Justicia de las Illes Balears que sean elegidos por el Parlamento de las Illes Balears lo serán por una mayoría de dos tercios de sus miembros». Art. 64 del Estatuto aragonés: 1. Se crea el Consejo de Justicia de Aragón. Una ley de las Cortes de Aragón determinará su estructura, composición, nombramientos y funciones dentro del ámbito de las competencias de la Co- 
En este modelo, la autolimitación de las funciones del órgano a aquellas que estén dentro del ámbito de las competencias de la Comunidad en materia de Administración de Justicia (es decir, de la administración o gestión de ésta) es constante. La referencia que se hace a lo que disponga la LOPJ es en sentido estricto innecesaria (pues para crear una comisión asesora en el ámbito de sus propias competencias o un foro de deliberación no le hace falta a la Comunidad permiso o habilitación de la $\mathrm{LOPJ}^{12}$ ) aunque puede servir para llamar la atención del legislador orgánico sobre la posibilidad de que dicha norma pueda atribuir alguna función (de informe, propuesta, etc.) a dicha comisión en el ámbito material sobre el que se proyectan sus funciones.

Por tanto, la primera conclusión que cabe extraer del examen de las normas estatutarias alusivas a los Consejos de Justicia es que siguen dos modelos netamente distintos $^{13}$, y que solo uno de ellos tiene que ver con el gobierno del Poder Judicial,

munidad Autónoma en materia de Administración de Justicia en los términos que establece el presente Estatuto y de acuerdo con lo dispuesto en la Ley Orgánica del Poder Judicial. 2. El Consejo de Justicia de Aragón tendrá la consideración, naturaleza, competencias y facultades que le atribuya la Ley Orgánica del Poder Judicial. Asimismo, participará en todos los procesos de designación que le atribuya dicha ley. Art. 42 del Estatuto de Castilla y León: «Mediante ley de las Cortes de Castilla y León se podrá crear el Consejo de Justicia de Castilla y León y establecer su estructura, composición y funciones dentro del ámbito de competencias de la Comunidad y de acuerdo con lo dispuesto en la legislación estatal»

${ }^{12}$ En Cataluña, por ejemplo, fue creado por Decreto 119/2002, de 16 de abril (modificado por los decretos 95/2003, de 1 de abril, y 370/2004, de 7 de septiembre) el Consejo de Justicia de Cataluña. El Decreto 377/2006, de 3 de octubre, cambió el nombre del órgano por el de Observatorio Catalán de la Justicia, según indica el preámbulo, «a fin de evitar la posible confusión con el órgano de nueva constitución que prevé el artículo 97 del Estatuto de autonomía de Cataluña». Finalmente, por Decreto 197/2009, de 22 de diciembre, del Observatorio Catalán de la Justicia, se da nueva regulación a éste observatorio, en tanto que «foro de análisis, reflexión, debate, participación y propuesta de actuación en materias relacionadas con la Administración de justicia en Cataluña, que tiene como finalidad promover la comunicación y el intercambio entre los operadores y las instituciones implicadas en esta materia» (art. 1.1).

${ }^{13}$ No compartimos, pues, la opinión de Ballester Cardell, para quien todos los consejos estatutarios responderían a un único modelo (órganos desconcentrados del CGPJ), diferenciándose únicamente en el mayor o menor grado de detalle de la correspondiente regulación: «(...) l'article 96 de l’Estatut de les Illes Balears, no presenta diferències substancials respecte d'aquells textos que regulen més escaridament la institució i se situa en la línea de permetre la territorialització del govern de la justicia a la nostra comunitat autónoma. (...) Queda clar que es parteix del reconeixement del Consell de Justícia de les Illes Balears com un òrgan que permet la desconcentració de les funcions del govern judicial a la comunitat autónoma». Vd. Ballester Cardell, M., «El Poder Judicial a les Illes Balears», en Blasco Esteve, A., dir., Comentaris a l'Estatut d'Autonomia de les Illes Balears. Thomson-Civitas, 2008, pág. 1069. También Álvarez Conde realiza dicha equiparación entre todos los Consejos existentes: «Las previsiones estatutarias existentes configuran a los Consejos de Justicia como órganos desconcentrados del CGPJ» cuando ya se ha visto por las razones indicadas que no es en modo alguno así. El propio au- 
situándose el otro completamente fuera de este ámbito para vincularse estrictamente con las competencias de la Comunidad en materia de Administración de Justicia. Esta diversidad de ámbitos sobre los que ejercerán sus funciones, la diversa forma de creación de los órganos (que cobran vida por ley autonómica en un modelo, y a través de la LOPJ en el otro) y su diferente naturaleza (órgano desconcentrado del CGPJ u órgano asesor de la Comunidad) así lo ponen de manifiesto. Así pues, el enjuiciamiento del Consejo de Justicia previsto en el Estatuto catalán por parte del TC, y la conclusión de éste acerca de su inconstitucionalidad, tendrán relevancia para el caso andaluz, pero no para el resto de Estatutos, que regulan otro tipo de Consejo al que no pueden alcanzar los reproches de inconstitucionalidad efectuados por el Tribunal. A continuación examinaremos en qué han consistido estos.

\section{EL CONSEJO DE JUSTICIA CONTENIDO EN EL ESTATUTO DE AUTONOMÍA DE CATALUÑA Y SU ENJUICIAMIENTO POR EL TRIBUNAL CONSTITUCIONAL}

\subsection{Premisa: la posibilidad de colaboración internormativa entre el Estatuto y la LOPJ}

El Título III del Estatuto catalán prevé el Consejo de Justicia bajo una premisa implícita: la de considerar que ello es posible en tanto que se hace con remisión a lo que determine la LOPJ, norma a la que corresponde hacer real la existencia de un Consejo que va a tener la naturaleza de órgano desconcentrado del CGPJ. Su previ-

\footnotetext{
tor, más adelante, indica al hablar del Consejo valenciano que el Estatuto «no configura al Consejo de Justicia como un órgano de gobierno del Poder Judicial», lo que contrasta con lo previamente dicho. Vd. Álvarez Conde, E., Reforma constitucional y reformas estatutarias, Iustel, 2007, págs. 487-488. Por el contrario, Lucas Murillo de la Cueva pone de manifiesto la dualidad descrita cuando indica que «debe subrayarse (...) la distinta orientación seguida por la reforma de los Estatutos de la Comunidad Valenciana, Aragón, Baleares y Castilla y León [respecto de los estatutos andaluz y catalán]. Diversidad que habrá que superar no solo en lo relativo a la exclusiva dimensión autonómica que parecen dar al Consejo de Justicia, sino en lo que respecta a la mención que hace el valenciano a la Sala de Gobierno de su Tribunal Superior, cuya permanencia da por supuesta». Vd. Lucas Murillo de la Cueva, P., «El Poder Judicial en Andalucía...», ob.cit., pág. 980. En términos menos rotundos, Ortells Ramos analiza las dos posibilidades de explicar la naturaleza del órgano, decantándose no obstante también por la de considerar que el Consell de Justícia valenciano no comparte la naturaleza de sus homónimos catalán o andaluz. Para el autor, aunque existiría un modo de interpretar que sí tiene tal naturaleza (entender que la remisión del art. 33.3 EACV hace que en realidad todo lo que el art. 33 dice del Consell deba entenderse condicionado a lo que disponga la LOPJ) se trata de una interpretación forzada. Vd. Ortells Ramos, M., «La Administración de Justicia», en Baño León, J. M., dir., Comentario al Estatuto de Autonomía de la Comunidad Valenciana, Thomson-Civitas, 2006, págs. 344-346 y 380-382.
} 
sión (art. 97) se remata indicando que el órgano actuará como órgano desconcentrado «de acuerdo con lo previsto en la Ley Orgánica del Poder Judicial». Sus atribuciones relativas a los órganos jurisdiccionales situados en el territorio de Cataluña se enumeran en el art. 98.2 indicando previamente que lo serán «conforme a lo previsto en la Ley Orgánica del Poder Judicial». En el apartado primero del mismo artículo, que enumera genéricamente los posibles orígenes de las diversas atribuciones del Consejo, uno de ellos es la LOPJ. Al regular su composición, el art. 99.1 remite a la LOPJ la determinación del modo como se nombrarán sus miembros entre personas pertenecientes a diversos sectores (jueces y magistrados, fiscales y juristas) y del número de miembros que corresponda nombrar al Parlament. Es cierto, sin embargo, que el precepto dispone, sin remisión alguna a la LOPJ, que será presidente/a del órgano quien a su vez presida el TSJ. Tampoco el art. 100 se remite a lo que disponga la LOPJ al regular el control de los actos del Consejo de Justicia. Pero en ambos casos, por coherencia con todo lo anterior, debiera interpretarse que la intervención de la LOPJ sería de igual modo imprescindible.

La colaboración internormativa se plasma igualmente en otros muchos apartados del Título III del Estatuto, en los que éste se remite a lo que disponga la LOPJ. La posibilidad de dicha colaboración está ligada con la distinción entre reserva absoluta y reserva relativa. Si la reserva que la Constitución hace a la LOPJ en su art. $122.1 \mathrm{o}$ a la ley orgánica en el art. $122.2^{14}$ fueran absolutas en el sentido de excluyentes de la posibilidad de que otra norma, como el Estatuto, pudiera intervenir colaborando en la regulación (por más que teniendo aquéllas la decisión final en cada caso) lógicamente la regulación estatutaria sería inconstitucional. Pero en la medida en que dicha reserva tolerase la intervención de otras normas (los Estatutos) para contribuir a dicha regulación proponiendo a la LOPJ una determinada opción normativa, o bien desarrollando, previa remisión por parte de ésta, determinados aspectos (como vemos la colaboración internormativa puede darse en dos direcciones $^{15}$ ), la regulación estatutaria sería factible ${ }^{16}$.

\footnotetext{
${ }^{14}$ Sin concretar en una ley orgánica concreta, lo que permitió como es sabido la existencia de una ley orgánica del CGPJ entre 1980 y 1985.

${ }^{15}$ Aun siendo la habitual aquella en la que la norma receptora de la reserva llama a otra a completarla, es sabido cómo ya los primeros Estatutos recurrieron a la técnica inversa, de modo que la LOPJ de 1985 vino a hacer realidad previsiones que se contenían en Estatutos anteriores y que remitían a ella. Si se discutiera esta posibilidad de colaboración internormativa cabría oponer, por una parte, que verdaderamente presupone del concurso de dos normas para dar lugar a una determinada regulación, y por otra, que la norma que remite contiene ya una regulación, una decisión sobre uno o varios temas, que la segunda norma, la receptora de la reserva, podrá hacer finalmente suya culminando dicha colaboración en el sentido propuesto por la primera.

${ }^{16}$ Otra cosa es, además, cuál sea el peso o alcance de cada norma en esa operación de colaboración internormativa. Como recuerda Viver Pi-Sunyer, hay aspectos, como los medios personales,
} 
Si del tenor literal del art. 122 CE no parece desprenderse nada expreso en este último sentido, no es menos cierto que la colaboración internormativa en este ámbito ha existido desde los primeros estatutos, en tanto que estos contenían previsiones (con la correspondiente remisión a lo dispuesto en la LOPJ) en cuestiones tales como las funciones de los TSJ y del resto de los órganos jurisdiccionales situados en el territorio, o el nombramiento del Presidente y los magistrados del TSJ, por ejemplo, cuestiones todas ellas sobre las que indudablemente se proyecta la reserva que la CE hace a la LOPJ, reserva que, si hubiera sido absoluta, hubiese hecho imposibles estas previsiones.

Las reformas estatutarias, con uno u otro grado de detalle, asumen de nuevo la posibilidad de la colaboración normativa, intensificándola y llevándola a nuevos ámbitos, uno de los cuales, como ya se ha visto, es el de los Consejos de Justicia.

\subsection{LA COLABORACIÓN INTERNORMATIVA EN EL ÁMBITO DE LA JUSTICIA EN LA SENTENCIA SOBRE EL ESTATUTO CATALÁN}

La primera cuestión radica en ver, por tanto, si el TC acepta dicha colaboración internormativa y de qué forma. Hay que empezar llamando la atención sobre el modo como la STC 31/2010 inicia en su FJ 42 el análisis del título III del EAC:

«(...) la función jurisdiccional, mediante la que tales normas [estatales y autonómicas] adquieren forma y contenido definitivos, es siempre, y sólo, una función del Estado. En definitiva, si el Estado autonómico arranca con una Constitución única, concluye con una jurisdicción también única, conteniéndose la diversidad de órganos y funciones en las fases del proceso normativo que media entre ambos extremos. La unidad de la jurisdicción y del Poder Judicial es así, en el ámbito de la concreción normativa, el equivalente de la unidad de la voluntad constituyente en el nivel de la abstracción. La estructura territorial del Estado es indiferente, por principio, para el Judicial como Poder del Estado. (...) Unidad orgánica y funcional [del Poder Judicial] que, asegurada en su sustancia con la atribución al Estado de la competencia exclusiva en materia de Administración de Justicia, es perfectamente compatible con el reconocimiento a las Comunidades Autónomas de determinadas competencias en el ámbito de la «administración de

en que el límite, por ejemplo, es el del estatuto de dicho personal, que es a lo que debiera ceñirse la regulación de la LOPJ. Y en medios materiales, por ejemplo, ni siquiera sería precisa una habilitación previa de la LOPJ para que el Estatuto regule. Vd. su respuesta a la encuesta del libro La justicia ante la reforma..., ob.cit., pág. 175. 
la Administración de Justicia», cuando así resulta de su titularidad sobre competencias propias de la vertiente puramente administrativa al servicio de la función jurisdiccional del Estado».

Una exposición tan rotunda, que equipara la unidad de la jurisdicción a la unidad de la voluntad constituyente, parece que debiera llevar a excluir toda posibilidad de colaboración internormativa. ¿Cómo podrían los Estatutos contribuir al diseño de algo que, indiferente por completo a la estructura territorial del Estado, según manifiesta el Tribunal, se sitúa en el mismo plano que la voluntad constituyente? Con un punto de partida tal, de hecho, extraña incluso que el Tribunal siga considerando posibles las competencias autonómicas en materia de administración de la Administración de Justicia ${ }^{17}$.

Pero en realidad, y con la excepción del Consejo de Justicia, el Tribunal no lleva hasta el extremo esa vehemente exaltación de la unidad del Poder Judicial ${ }^{18}$, y admite posteriormente, y pese a todo lo que antes había proclamado de modo

${ }^{17}$ Véase la crítica de M.A.Aparicio a esta proclama inicial del Tribunal, señalando, por un lado, que «se hace difícil el digerir que cualquier tipo de norma (y no sólo la de los entes autonómicos) adquiera forma y contenido definitivos mediante la función jurisdiccional, con lo que, parece indicarse, hasta que una norma no es aplicada jurisdiccionalmente (... ¿cuántas veces?) ni su forma ni su contenido son definitivos». Por otro lado, pone de manifiesto la impropiedad de equiparar como idénticos los conceptos de jurisdicción y poder judicial. Ni aquella és única, recuerda, ni éste opera unitariamente en el ámbito de la concreción normativa. Finalmente, señala la incorrección de señalar que «la unidad de la jurisdicción y del Poder Judicial es así, en el ámbito de la concreción normativa, el equivalente de la unidad de la voluntad constituyente en el nivel de la abstracción», pues lógicamente «si el poder judicial fuera múltiple, el poder constituyente seguiría siendo siempre único». Vd. Aparicio Pérez, M.A., «Comentario a la STC 31/2010, sobre el Poder Judicial», Revista Catalana de Dret Públic, número especial disponible en internet (http://www10.gencat.net/eapc_revistadret), págs. 3-4. También Balaguer Callejón ha hecho notar cómo la formulación del Tribunal llevaría a afirmar que «no existe en el Estado federal unidad del ordenamiento a través de la función normativa. Es decir, exactamente lo contrario de lo que la realidad nos dice pues la normatividad de la Constitución ha ido vinculada históricamente a la formulación federal en la que se plasma, inevitablemente, la unidad de eso que los juristas llamamos «poder constituyente», en la propia Constitución federal». Vd. Balaguer Callejón, F., «Las cuestiones institucionales en la STC 31/2010, de 28 de junio", en El cronista del Estado social y democrático de Derecho, 15, 2010, pág. 67.

${ }^{18}$ De lo que se duele en su voto particular el Magistrado Conde Martín de Hijas: «Cuando se proclama, como se hace en el FJ 42 de la Sentencia, una doctrina tan esclarecedora y brillante, (que comparto plenamente), sobre el significado de la unidad del Poder Judicial en la caracterización del Estado de las Autonomías, me sorprende cómo a la hora de enjuiciar los preceptos cuestionados del título III, empezando por el de su art. 95, se puede desembocar en los niveles de tolerancia en que se incurre al pronunciarse sobre su constitucionalidad o inconstitucionalidad» (apartado 17 de su voto). 
tan enfático, la colaboración internormativa de los Estatutos con la LOPJ, salvo, hay que insistir, en el caso del citado Consejo. Y no solo la admite, sino que se vale de ella de modo constante para establecer la interpretación conforme a la Constitución que deberán recibir una serie de preceptos.

En efecto, así ocurre en el caso del art. 95.1 EAC, que se refiere a la competencia del TSJ en los diversos órdenes, con remisión a la LOPJ, o a su función de protección de los derechos estatutarios, con remisión en este caso a las leyes. También cuando se interpreta el art. 95.2 al referirse éste a la competencia reservada al TS para la unificación de doctrina, previsión sobre la que el TC señala que la LOPJ es la única constitucionalmente habilitada para determinar el alcance de las funciones del TS, de modo que el precepto estatutario no puede ser entendido en el sentido de que se esté refiriendo a un tipo concreto de recurso o de que pueda limitar las opciones de la LOPJ. De nuevo el art. 95.4, al referirse al recurso de revisión, es interpretado en el sentido de que ha de considerarse que se remite a la LOPJ para que sea ésta la que adopte la regulación correspondiente: «No estamos, por tanto, ante una norma estatutaria atributiva de competencias judiciales, sino ante un precepto que asume, sin condición, cuanto sobre esa materia decida, con perfecta libertad, el legislador estatal competente» (FJ 45).

Igualmente en el FJ 50 se admite la regulación estatutaria contenida en el art. 101.3 EAC, relativa a la posibilidad de optar por una u otra lengua oficial en las pruebas de los concursos y oposiciones celebradas en Cataluña, porque el ejercicio de ese derecho «requiere la inexcusable intervención del legislador estatal; concretamente, del legislador orgánico del Poder Judicial a quien corresponde precisar las modalidades y requisitos de ejercicio del derecho de opción lingüística contemplado en el Estatuto». También en materia lingüística, la regulación del art. 102.1 EAC sobre el conocimiento adecuado y suficiente del catalán por parte de magistrados, jueces y fiscales se configura por el Tribunal como un deber genérico de conocimiento, consecuencia de la cooficialidad, que deberá ser en todo caso enjuiciado cuando las leyes competentes lo concreten.

En lo relativo al conocimiento del Derecho propio, «no deja de ser una legítima pretensión del legislador estatutario — en tanto que competente para la defensa y promoción de aquella lengua y de aquel Derecho — respecto de la acción legislativa del único competente para cuanto se refiere a la Administración de Justicia en sentido propio, esto es, para las Cortes Generales, que, con perfecta libertad, habrán de determinar, en su caso, la forma y el alcance con que esa pretensión pueda formalizarse en una condición jurídica de Derecho positivo» (FJ 51).

En materia de personal, la competencia normativa a que se refiere el art. 103 EAC es interpretada bajo idéntica premisa: «la previsión de que dicha compe- 
tencia ha de ejercerse dentro del respeto al estatuto de aquel personal establecido por la Ley Orgánica del Poder Judicial, es evidente que por sí sola excluye toda posible infracción de dicho estatuto jurídico y de la única Ley competente para su regulación. Por ello, la concreta relación de materias cuya regulación se incluye en esa competencia según el propio art. 103.1 EAC sólo puede entenderse por estricta referencia a las previsiones de la Ley Orgánica del Poder Judicial y con arreglo a ellas deben ser interpretadas y entendidas, en su contenido y en su alcance. Lo mismo ha de decirse respecto de las funciones que el apartado 2 del art. 103 EAC incluye en «la competencia ejecutiva y de gestión (...)» (FJ 52). Y también se admite que el art.103.3 EAC prevea la creación por ley del Parlament de Cataluña de cuerpos autonómicos de funcionarios al servicio de la Administración de Justicia porque ello se hará dentro del marco dispuesto por la LOPJ «de manera que tal creación sólo es posible si esa Ley Orgánica lo permite y en los términos en que lo haga» (FJ 52).

Igualmente la remisión del Estatuto a lo que disponga la LOPJ en materia de oficina judicial permite salvar la previsión del art. 105 EAC, y del mismo modo rechaza el TC que éste invada el ámbito de la planta judicial, y lo hace de un modo sumamente expresivo: «Es de recordar, una vez más, que el art. 105 EAC sólo atribuye competencias de acuerdo con la Ley Orgánica del Poder Judicial, lo que hace imposible, por principio, la contradicción entre el precepto estatutario y la norma constitucionalmente habilitada para la regulación de la materia en cuestión» (FJ 53).

Por último, la previsión de que la Generalitat podrá crear secciones o juzgados, por delegación del Gobierno del Estado, en los términos previstos por la LOPJ, que incide en un ámbito, el de la definición y establecimiento de la planta «claramente integrada en el ámbito de la Administración de Justicia del art. 149.1.5 CE», no infringe ésta porque estamos ante «un precepto cuyas previsiones quedan expresamente sometidas a la realización de condiciones indisponibles para el poder público autonómico y enteramente reservadas a la libertad del Estado» (FJ 55).

Esta enumeración de los principales casos en que la sentencia recurre a la colaboración internormativa para salvar la constitucionalidad de los preceptos estatutarios permite comprobar que la misma se proyecta sobre los ámbitos más variados, y que tiene la virtualidad de evitar cualquier posibilidad de inconstitucionalidad de la regulación estatutaria. El FJ 53 es expresivo al respecto: la remisión estatutaria a la LOPJ «hace imposible, por principio, la contradicción entre el precepto estatutario y la norma constitucionalmente habilitada».

En todos los casos en que opera la colaboración internormativa como remedio a la posible inconstitucionalidad se entiende, lógicamente, que la reserva a la 
LOPJ es relativa, por lo que el Estatuto puede plantearle opciones de regulación. TSJ, protección de los derechos, personal, conocimientos de lengua y Derecho propios, planta judicial... en ámbitos tan variados como estos la colaboración internormativa se admite con naturalidad ${ }^{19}$. Cosa muy distinta, como veremos de inmediato, es lo que ocurre en el ámbito de los consejos de justicia.

\subsection{ELEMENTOS DEL EXAMEN POR PARTE DEL TC DEL CONSEJO DE JUSTICIA}

\subsubsection{La exclusión de la colaboración internormativa}

Cuando el art. 95.4 EAC atribuye al TSJ «la resolución de los recursos extraordinarios de revisión que autorice la ley contra las resoluciones firmes dictadas por los órganos judiciales de Cataluña», cualquiera podría pensar que se está atribuyendo al TSJ una concreta función jurisdiccional, lo que únicamente podría hacer la LOPJ. Para el Tribunal, en cambio, «no estamos (...) ante una norma estatutaria atributiva de competencias judiciales, sino ante un precepto que asume, sin condición, cuanto sobre esa materia decida, con perfecta libertad, el legislador estatal competente». Es decir: el Estatuto no dota al TSJ de una función, sino que manifiesta que éste la tendrá si y en la medida en que la ley competente se la otorgue. Así pues, cuando el Estatuto prevé la existencia del Consejo de Justicia con una determinada naturaleza y una serie de atribuciones, en la medida en que ello se hace con remisión a lo que la LOPJ disponga, la aplicación de la anterior doctrina debiera llevar a afirmar, como es obvio, que no estamos ante una norma estatutaria creadora de un órgano, sino ante la previsión de que el órgano existirá si y en la medida en que la LOPJ así lo disponga. Este sería el resultado de aplicar también aquí la técnica de la colaboración internormativa.

Ello, como es bien sabido, no es así en la sentencia. Y para que no sea así, se combinan dos elementos: en primer lugar, una cierta confusión sobre la naturaleza del órgano enjuiciado; en segundo lugar, el paso en este ámbito de la reserva relativa a la absoluta sin mayor explicación del por qué. Todo lo anterior, sorprendentemente, no lleva, como se verá más adelante, a la conclusión de la declaración de inconstitucionalidad del órgano sin más, sino que conduce a un resultado intermedio por el que se declara inconstitucional parte de la regulación, mientras que otra par-

${ }^{19} \mathrm{Y}$ con igual extensión, lo que de nuevo obliga a recordar que el papel de la LOPJ (y correspectivamente, de los Estatutos) puede tener en cada caso matices diferentes en su alcance, como ya se apuntó en la nota a pie núm. 13. El Tribunal, no obstante, no entra en esta cuestión. 
te queda en pie para que el Tribunal proceda a la reconversión del órgano en otro.

El Tribunal opone, a la regulación por el Estatuto del Consejo de Justicia, la afirmación de que el Poder Judicial no puede tener más órgano de gobierno que el CGPJ: ningún otro órgano, continúa diciendo el Tribunal, puede ejercer la función de gobierno de los órganos jurisdiccionales integrados en el Poder Judicial. En segundo lugar, el estatuto y funciones del CGPJ quedan expresamente reservados al legislador orgánico, y ninguna ley que no sea la LOPJ puede determinar la estructura y funciones del Consejo (FJ 47).

Lo primero, así expuesto, parece ignorar que el propio art. 104.2 LOPJ, encuadrado en el Título I del Libro II, bajo el título «De los órganos del gobierno del Poder Judicial» (en plural) prevé que el CGPJ sea ayudado por otros órganos en sus funciones de gobierno:

«El gobierno del Poder Judicial corresponde al Consejo General del Poder Judicial, que ejerce sus competencias en todo el territorio nacional, de acuerdo con la Constitución y lo previsto en la presente Ley. Con subordinación a él, las salas de gobierno del Tribunal Supremo, de la Audiencia Nacional y de los Tribunales Superiores de Justicia ejercerán las funciones que esta Ley les atribuye, sin perjuicio de las que correspondan a los Presidentes de dichos Tribunales y a los titulares de los restantes órganos jurisdiccionales $»^{20}$.

Lo segundo, la reserva absoluta (ninguna ley que no sea la LOPJ puede referirse a esta materia) contrasta, como bien se ve, con la previa admisión de que los Estatutos puedan aludir a cuestiones tan indudablemente reservadas a la LOPJ como las funciones de los TSJ o a las funciones de los órganos jurisdiccionales sitos en la Comunidad, materias que no se ve por qué han de seguir, en lo tocante a la reserva, un régimen distinto al previsto para el gobierno del Poder Judicial ${ }^{21}$. Pese a ello, el Tribunal excluye en este ámbito la posibilidad de la colaboración internormativa.

${ }^{20}$ Es interesante a este respecto el recordatorio que realiza Xiol Ríos, que subraya cómo la LOPJ «atribuye a las Salas de Gobierno de los TSJ (además de las funciones propiamente de gobierno interno del tribunal respectivo) funciones gubernativas que exceden del ámbito orgánico del tribunal correspondiente y se extienden a todos los órganos judiciales del territorio (...). La integridad institucional del CGPJ se logra, e el sistema actual, reservándole directamente el ejercicio de las competencias más importantes y reconociendo su potestad para revisar las decisiones de los órganos de gobierno inferiores a él por vía de recurso». Vd. Xiol Ríos, J.A., «El Poder Judicial y la construcción del Estado autonómico», en VVAA, La justicia ante la reforma ..., ob.cit., págs. 88-89.

${ }^{21}$ Por otra parte, el hecho de que la propia LOPJ haya sido complementada por otras normas (los —impropiamente— llamados «reglamentos orgánicos» del personal, o los reglamentos del CGPJ) muestra igualmente cómo se han ido estableciendo, en ámbitos diferentes, líneas de colaboración internormativa incompatibles con una noción de reserva absoluta. 


\subsubsection{La confusión sobre la naturaleza del órgano}

Pero es que, además, el enjuiciamiento del Consejo de Justicia culmina de modo revelador con la consideración que de su naturaleza hace el TC: «Ahora bien, la impropiedad constitucional de un órgano autonómico cualificado en los términos del art. 97 EAC no significa fatalmente la inconstitucionalidad misma del órgano en cuestión (...)» (FJ 47). El lapsus es significativo. Es obvio que el Consejo de Justicia que regula el Estatuto no es un órgano autonómico (a diferencia de lo que ocurre en el caso de otros estatutos, como se vio al inicio de estas páginas) sino que se pretende que sea un órgano desconcentrado del CGPJ. No ignora esto el Tribunal, pero en el fundamento citado parece como si por un momento lo olvidase. Ciertamente, si lo que el Estatuto hubiese pretendido hacer hubiera sido crear un órgano autonómico de gobierno del Poder Judicial, es obvio que tal pretensión resultaría inconstitucional, pero no es esto lo que el Estatuto quiere hacer, y el Tribunal no hubiera debido perder esto de vista ni siquiera en esa ocasión en que por descuido le atribuye la naturaleza que no tiene.

El Tribunal, pues, mezcla las referencias al carácter de órgano desconcentrado del CGPJ que realiza el Estatuto con una cierta concepción subyacente (que se hace expresa en el párrafo mencionado) del citado Consejo de Justicia como órgano autonómico, lo que determina fatalmente su inconstitucionalidad, al unirse dicha concepción con la exclusión, antes citada, de la colaboración internormativa en este subámbito. Y yendo más allá de esto, incluso puede afirmarse, siguiendo a Aparicio, que en realidad, por encima de naturalezas o confusiones, lo que suscita el rechazo del Tribunal es la mera posibilidad de que un Estatuto prevea «la existencia hipotética de un órgano de gobierno judicial territorial ajustado a las previsiones que en su momento contuviera la LOPJ. El anatema procede de la simple previsión de la posible naturaleza del órgano $(\ldots) »^{22}$.

\subsubsection{La distinción entre atribuciones y la reinvención del órgano}

\section{A) La distinción entre atribuciones}

Si, por todo lo dicho, el Consejo de Justicia previsto en el Estatuto debía ser inconstitucional (pues solo la LOPJ podría regularlo, y porque de ningún modo podría otro órgano que no fuese el CGPJ ocuparse del gobierno de los jueces, lo que contrasta tanto con la previsión ya mencionada del art. 104.1 LOPJ como

${ }^{22}$ Vd. Aparicio Pérez, M.A., ob.cit., pág. 5. 
con el hecho de que el Consejo de Justicia estaba llamado a pertenecer al propio CGPJ) lo que de inmediato sorprende sobremanera es que el Consejo de Justicia no desaparezca sino que se reinvente.

Ello se hace a través de un singular deslinde de atribuciones: las que de ningún modo podrían pertenecer a un Consejo de Justicia configurado como órgano autonómico (pues si verdaderamente el TC hubiera aceptado su naturaleza de órgano desconcentrado del CGPJ hubiera bastado con decir que tales funciones las tendría en la medida en que la LOPJ aceptase atribuírselas) y las que sí que podría tener de ser meramente eso, un órgano de la Comunidad.

Las primeras, que «incurren en clara inconstitucionalidad, por tratarse de atribuciones típicas de un órgano de gobierno del Poder Judicial» son las contenidas en los apartados a), b), c), d) y e) ${ }^{23}$ del art.98.2. Claro está que la inconstitucionalidad es tal en la medida en que se considera (como el TC parece hacer) que esas funciones de gobierno se quieren conferir a un órgano autonómico, pero no lo sería en absoluto si se entendiese que se quieren atribuir a un órgano del propio CGPJ, y en la medida en que la LOPJ así lo disponga. Así pues, para llegar a la conclusión de inconstitucionalidad ha de partirse previamente de la mutación de la naturaleza del órgano, antes citada.

Las segundas, que se acomodan a la Constitución por poder corresponder al parecer sin problema alguno a un órgano de carácter autonómico, son las contenidas en los apartados f), g) y h) del art. $98.2^{24}$. Tales atribuciones «se compa-

${ }^{23}$ Como recuerda el propio Tribunal, son: «a) participación en la designación de presidentes de órganos judiciales, b) expedición de nombramientos y ceses de Jueces y Magistrados temporales, c) funciones disciplinarias sobre Jueces y Magistrados, d) inspección de Tribunales y e) información sobre recursos de alzada contra acuerdos de los órganos de gobierno de los Tribunales y Juzgados de Cataluña». La mayor parte, de todos modos, tienen un claro carácter no decisorio. Como recuerda Porras Ramírez, «la atribución que los mencionados Estatutos hacen de las mismas a dichos órganos territoriales no sea a costa del Consejo General del Poder Judicial, sino de dichas Salas de Gobierno, redundando en el ejercicio de funciones de informe, consulta y propuesta al Consejo General del Poder Judicial. No se trata, por tanto, de competencias que afecten al núcleo esencial del gobierno del Poder Judicial, las cuales corresponden, en exclusiva, al órgano de relevancia constitucional previsto por la Constitución, sino que, más bien, se trata de competencias de gobierno, manifiestamente delegables o transferibles a esos órganos territoriales, de carácter auxiliar, a crear en las Comunidades Autónomas». Vd. Porras Ramírez, J.M., «La justicia en los Estatutos de Autonomía de segunda generación», Teoría y Realidad Constitucional, 24, 2009, págs.. 280281.

${ }^{24}$ En palabras del propio Tribunal, se trata de: «f) precisar y aplicar, cuando proceda, en el ámbito de Cataluña, los reglamentos del CGPJ, g) información sobre propuestas en materia de organización y demarcaciones, h) presentación de una memoria al Parlamento e i) reiterativo del art. 98.1 EAC». 
decen sin dificultad con el ámbito de las competencias asumibles por la Comunidad Autónoma en relación con la «administración de la Administración de Justicia», [y] su ejercicio por un órgano autonómico específico como es el Consejo de Justicia de Cataluña no plantea ningún reparo constitucional a la existencia de este último, en el bien entendido de que no puede ser cualificado en los términos utilizados por el art. $97 \mathrm{EAC»} \mathrm{(FJ} \mathrm{48).}$

Lo sorprendente viene cuando comprobamos que una de las funciones que el Tribunal entiende que es perfectamente acomodable dentro de las competencias autonómicas en materia de administración de la Administración de Justicia es la del apartado f) del art.98.2, es decir, «precisar y aplicar, cuando proceda, en el ámbito de Cataluña, los reglamentos del CGPJ». Aquí la sorpresa es inevitable, pues lógicamente precisar un reglamento implica una labor de concreción del mismo, de integración de posibles lagunas, de contribución, en definitiva, con la labor normativa. ¿Verdaderamente corresponde al ámbito de competencia autonómica que atañe a la administración de la Administración de Justicia precisar los reglamentos que dicte el CGPJ? Lo que hasta ahora venía estableciendo la jurisprudencia, al hilo de las diversas reformas de la LOPJ en este punto, era algo distinto.

En efecto, la jurisprudencia relativa a la potestad reglamentaria del CGPJ se recoge en las SSTC 108/86 y 105/2000, que han analizado dicha cuestión (al hilo de las impugnaciones de la LOPJ que las motivaron) de un modo no exento de contradicciones $^{25}$. En síntesis, esta última sentencia de 2000 viene a concluir que es el CGPJ el único legitimado para dictar reglamentos relativos al estatuto jurídico de jueces y magistrados, y sobre las condiciones accesorias del mismo. El Gobierno y las CCAA, en su respectivo ámbito, no ostentan competencias ni para regular tales cuestiones ni para desarrollar los reglamentos del CGPJ. Su potestad reglamentaria se proyecta exclusivamente sobre el ámbito de la administración de la Administración de Justicia que les es propio.

Indica el Tribunal que «no cabe descartar que al regular, legítimamente y sin excesos, materias de su competencia puedan afectar indirecta o reflejamente (...) a determinadas condiciones accesorias para el ejercicio de los indicados derechos y deberes [de jueces y magistrados]. La expresión «afectar»

${ }^{25}$ Sobre ambas sentencias y la normativa de la LOPJ de la que traían causa, véase: Barceló Serramalera, M., y Gerpe Landín, M., «La potestad reglamentaria de desarrollo de la Ley Orgánica del Poder Judicial», Revista Jurídica de Catalunya, 102, 2003, págs. 129-164; Porras Ramírez, J.M., «Fundamentos, naturaleza, extensión y límites de la potestad reglamentaria del Consejo», Revista de Estudios Políticos, 87, 1995, págs. 239-257, Navas Sánchez, M.M., Poder Judicial y sistema de fuentes. La potestad normativa del Consejo General del Poder Judicial, Madrid, Civitas, 2002; Folguera Crespo, J., «La potestad reglamentaria del Consejo», Poder Judicial, 62, 2001, págs. 313-374. 
a una materia no se identifica con regular la misma» (FJ 9). Y «en la medida en que al ejercer las facultades derivadas de uno de ellos se afecte a los aspectos accesorios del estatuto judicial, aun sin regularlos, el título competencial en cuestión resultará sometido a los mismos límites que rigen respecto de los reglamentos del Consejo dictados para regular los aspectos secundarios del ejercicio de los derechos y deberes de Jueces y Magistrados» (FJ 9). Tales límites son los de no poder innovar los citados derechos y deberes ni alterar el estatuto judicial en su conjunto.

Por tanto: la potestad reglamentaria autonómica en este ámbito no le permite entrar a regular en el ámbito que es propio del Consejo, por más que, en el caso de que mientras regula lo que sí que es propio de la competencia autonómica se produzca indirectamente algún tipo de afectación al estatuto judicial, la sentencia recuerda los límites a que dicha afectación estará sometida.

La interpretación del Tribunal no deja de ser un tanto confusa. Pero puede estarse de acuerdo con Folguera Crespo, a quien siguen igualmente Barceló Serramalera y Gerpe Landín, cuando sostiene que la mención de ésta a los reglamentos del Gobierno o de las Comunidades Autónomas «resulta ser, no una habilitación legal para proceder a tal afectación sino una simple cláusula de garantía para el caso de que indirecta o mediatamente se produzca semejante efecto no deseado» ${ }^{26}$. Lo que regulan Gobierno o CCAA es, pues, no el estatuto jurídico de los jueces, sino las cuestiones que son propias de la administración de la Administración de Justicia.

Por ello mismo, no se entiende que a un órgano autonómico se le pueda reconocer la capacidad de precisar los reglamentos del CGPJ (reglamentos que se proyectan sobre los ámbitos propios de su función de gobierno del Poder Judicial) pues tal labor de precisión se traduciría necesariamente en una función de co-reglamentación que ya hemos visto que un órgano autonómico no puede tener. La función estaba pensada, en el Estatuto, para que la tuviera un órgano del propio CGPJ (y cabe pensar que con límites: precisar en los casos imprescindibles, sin entrar a regular propiamente el estatuto judicial ${ }^{27}$ ). En un órgano meramente autonómico, en cambio, desborda las funciones posibles de éste.

${ }^{26}$ Vd. Folguera Crespo, J., «La potestad reglamentaria...», ob.cit., pág. 329.

${ }^{27}$ Para Lucas Murillo de la Cueva, lo deseable sería incluso prescindir de esa función de precisar, y «limitar a la mera aplicación» esa referencia a precisar y aplicar. Vd. Lucas Murillo de la Cueva, P., «El Poder Judicial en Andalucía...», ob.cit., pág. 977. 
B) La reinvención del órgano

Sea como fuere, de lo anterior deriva el Tribunal la posibilidad de la existencia del Consejo de Justicia, solo que de un Consejo de Justicia con una naturaleza (órgano autonómico) que no tiene nada que ver con la que le había otorgado el Estatuto, y dotado de una parte de sus iniciales funciones (alguna de ellas sorprendente teniendo en cuenta la naturaleza mencionada) pero no del resto. Así pues, la regulación estatutaria ha mutado totalmente, hasta el punto de que tras la sentencia (que en este ámbito se corresponde perfectamente con la categoría de las sentencias manipulativas) el órgano que podrá crearse a partir de las previsiones del Estatuto no tendrá nada que ver con el que el Estatuto quería crear realmente ${ }^{28}$.

Un segundo efecto (no se sabe si buscado o casual) derivado de la sentencia es el de la consecución de la homogeneización de los consejos de justicia estatutarios. Como se ha visto al inicio, de las regulaciones estatutarias se derivaba una dualidad de consejos, solo uno de los cuales tenía que ver con el gobierno del Poder Judicial. Tras la sentencia, solo será posible uno de los dos modelos, el ajeno a las funciones de gobierno, aunque con la particularidad de que una de sus funciones (precisar los reglamentos del CGPJ) sí que incidiría en ese ámbito salvo que la LOPJ acabe por desactivarla, que es lo que se supone que ocurrirá si no se opta por resucitar los consejos del modelo «órgano desconcentrado» mediante reforma futura de dicha ley orgánica.

No acaban aquí las cuestiones problemáticas: es un órgano autonómico, al que se le ha despojado de (casi) todas las funciones que puedan entrar en contacto con el gobierno del Poder Judicial, y desde luego se le ha desvinculado radicalmente de todo nexo o vinculación con el CGPJ, pero a pesar de todo ello se mantiene el papel de la LOPJ en la determinación de quiénes serán sus miembros. El

\footnotetext{
${ }^{28}$ Critica este hecho en su voto el Magistrado Conde Martín de Hijas: «Si el concreto órgano establecido en el art. $97 \mathrm{EAC}$ es el que es (y no otro que, en su caso, hubiera podido ser), no me parece correcto que al tiempo que se declara su inconstitucionalidad se pretenda salvar la constitucionalidad posible de un órgano diferente, que el Estatuto no ha creado en este caso» (apartado 17 del voto). Para el Magistrado Delgado Barrio «la Sentencia inventa un órgano nuevo, un Consejo de Justicia que es otra cosa, —un órgano de la Generalitat — para ejercer algunas de las funciones del Consejo de Justicia que creaba el Estatuto» (apartado 17 de su voto). Para el Magistrado Rodríguez Arribas «Después de haber declarado, correctamente, la inconstitucionalidad del art. 97 y una vez anulado éste porque define un órgano (el Consejo de Justicia de Cataluña) que no cabe en la Constitución, carece de sentido alguno que ese órgano, ya inexistente, reaparezca para, no obstante, conservar algunas competencias y además se mantengan otros preceptos que regulan su composición y solo parcialmente son declarados inconstitucionales» (apartado 8 de su voto).
} 
art. 99.1 EAC disponía una composición del órgano pensando en su configuración como órgano desconcentrado del CGPJ, de modo que estaría compuesto por «los miembros que se nombren, de acuerdo con lo previsto por la Ley Orgánica del Poder Judicial, entre Jueces, Magistrados, Fiscales o juristas de reconocido prestigio», y preveía que su presidencia correspondiera al Presidente del Tribunal Superior de Justicia de Cataluña. No aceptándose que el Estatuto regulase el Consejo de Justicia, lo propio hubiera sido no aceptar tampoco que previese su composición.

Pero a raíz de la conservación del órgano bajo forma mutada, el Tribunal decide conservar también el precepto alusivo a la composición, solo que declarando inconstitucional la previsión relativa a la presidencia, porque comportaría que fuese el Estatuto quien atribuyera al Presidente una función no jurisdiccional, cuando el art. 117.4 CE establece que los jueces y tribunales «no ejercerán más funciones que las señaladas en el apartado anterior [el ejercicio de la función jurisdiccional] y las que expresamente les sean atribuidas por Ley en garantía de cualquier derecho». Esta última excepción al principio general de dedicación única al ejercicio de la función jurisdiccional, dice el TC, no puede establecerla un Estatuto. Por la misma regla de tres, cabría pensar, también sería inconstitucional que el art. 99.1 EAC prevea que serán miembros del Consejo jueces y magistrados, pero en este caso el TC salva la constitucionalidad considerando que la remisión que el Estatuto hace a la LOPJ determina que sea ésta quien en realidad establezca, si lo desea, la excepción mencionada. Esta aceptación, en este punto concreto, de la colaboración internormativa, hubiese podido extenderse igualmente a la previsión declarada inconstitucional, estableciéndose que la misma solo podría ser efectiva cuando la única norma que puede prever ese tipo de excepciones, la LOPJ, acogiera esa previsión.

Lo que interesa remarcar es que, en definitiva, el Tribunal establece que será la LOPJ la norma a la que «con plena libertad le corresponde determinar entre qué profesionales de los mencionados en el precepto pueden ser nombrados los componentes del Consejo de Justicia y, en su caso, incluir entre ellos a Jueces y Magistrados, habilitándolos, de esta forma, para el ejercicio de funciones ajenas a la potestad jurisdiccional». La pregunta subsiguiente es si en un órgano que, tras el enjuiciamiento del Tribunal, ha quedado como meramente autonómico, de asesoramiento de la Comunidad en el ámbito de sus competencias en materia de administración de la Administración de Justicia, tiene mucho sentido que sea la LOPJ la que tenga que determinar qué profesionales, de qué sectores y en qué número pueden ser nombrados miembros del Consejo de Justicia. Lo lógico es entender que la LOPJ contendrá una mera habilitación autorizando a los jueces y magistrados a formar parte de dicho Consejo si la Comunidad se lo propone, 
pero sin adentrarse en más detalles sobre la composición, el número de miembros, la presencia de miembros no judiciales, etc., dado que estamos ante un órgano puramente autonómico. Otra solución sería difícilmente explicable.

\subsection{Escenarios tras la sentencia}

La sentencia, en el aspecto que tratamos, resulta un modelo de cómo intentar integrar en una sola decisión varias opciones incompatibles entre sí. A quienes clamaban por la inconstitucionalidad del órgano, se les ofrece ciertamente lo solicitado, aunque sea al precio de tener que imaginar que el órgano que el Estatuto diseñaba era un órgano autonómico a fin de poder combatirlo con mayor facilidad. A quienes sostenían su plena constitucionalidad, se les ofrece un premio de consolación («otro» consejo de justicia) aunque sea al precio de rediseñar y mutar el que el Estatuto regulaba, y, por si ello fuera poco, se les añade una promesa futura de resurrección posible del tipo de órgano ahora fenecido.

En efecto: el FJ 47, tras reiterar que solo la LOPJ puede regular la estructura y funciones del CGPJ, añade que ello podrá hacerlo «dando cabida, en lo que ahora interesa, y en su caso, a eventuales fórmulas de desconcentración que, no siendo constitucionalmente imprescindibles, han de quedar, en su existencia y configuración, a la libertad de decisión del legislador orgánico con los límites constitucionales antes expresados» ${ }^{29}$.

Así pues, lo que se ha perdido en el Estatuto podría recuperarse mediante reforma de la LOPJ. Claro está que, mientras tanto, ya se ha dado carta de naturaleza a los Consejos de Justicia asesores de las Comunidades, a los que la LOPJ tendrá que referirse, cuando menos, en lo relativo a su composición, como hemos visto. Podríamos encontrarnos en el futuro, por tanto, en cada una de las Comunidades cuyo estatuto lo haya previsto, con una dualidad de Consejos de Justicia: los estatutarios asesores, desligados esencialmente del gobierno del Poder Judicial y que inicialmente no se hallaban (con tal naturaleza) en Estatutos como el catalán o el an-

${ }^{29}$ Únicamente el Magistrado Rodríguez Arribas, en su voto particular, considera imposible incluso esta solución: «la unidad en sentido estricto del Consejo General del Poder Judicial impide una descentralización, desconcentración o como se quiera llamar, que acabaría multiplicando por diecisiete el órgano de gobierno del Poder Judicial, que la Constitución quiso único, como lo es el propio Poder al que gobierna. La imposibilidad constitucional de crear «consejos desconcentrados» del Consejo General del Poder Judicial, lo es por razones materiales y nadie, tampoco el legislador orgánico estatal, puede hacerlo». Pero obviamente la creación de órganos internos dentro de otro no hace que es se descomponga en varios, perdiendo su unidad. Podrá hacerlo más complejo interiormente, pero no, desde luego, trocearlo en diecisiete consejos generales del Poder Judicial. 
daluz; y los Consejos creados por la LOPJ como órganos desconcentrados del CGPJ que, aun no habiendo sido acogidos en la mayor parte de estatutos reformados, es de suponer que, de plasmarse en la LOPJ, se generalizarán a lo largo de todo el territorio. Dos órganos, dos naturalezas, dos nombres (pues es de suponer que también en el nombre deberán distinguirse) y ello multiplicado ${ }^{30}$.

Cabe razonablemente preguntarse si tanta complicación no hubiera podido evitarse aplicando al caso del Consejo de Justicia el mismo principio de colaboración internormativa que permite en otros tantos ámbitos que la regulación estatutaria conviva con la propia de la LOPJ. Después de cuatro años de oír en ámbitos no jurídicos (y en ocasiones, incluso en los jurídicos) que el Estatuto pretendía crear un poder judicial catalán, el Tribunal puede haber sentido la tentación de resolver mediante la declaración de inconstitucionalidad lo que hubiera podido solucionarse con la aplicación de aquel principio o técnica. La opción finalmente adoptada, sin embargo, no hará desaparecer aquella acusación falaz, pero creará una serie de problemas que no harán más que aumentar el recelo contra todo lo que se asemeje a aproximación del Poder Judicial al modelo de Estado. Recelo, por cierto, al que el propio Tribunal pone voz de manera sorprendentemente rotunda al inicio de su argumentación: «la unidad de la jurisdicción y del Poder Judicial es así, en el ámbito de la concreción normativa, el equivalente de la unidad de la voluntad constituyente en el nivel de la abstracción. La estructura territorial del Estado es indiferente, por principio, para el Judicial como Poder del Estado» (FJ 42).

Title

The Councils of Justice in the current statutory reform process and its future prospects

\section{Summary}

1. The approach of the government of the Judiciary to the composite structure of the State and the current statutory reforms. 1.1. Prece-

\footnotetext{
${ }^{30}$ Si esta dualidad se acaba dando, entonces no sería preciso otorgar atribuciones a los Consejos de Justicia (órganos desconcentrados) que no tuvieran que ver con el gobierno del Poder Judicial y sí meramente con la administración de la Administración de Justicia y las competencias de la Comunidad en este ámbito, pues para esto último ya estaría el Consejo de Justicia estatutario. Se evitaría así que el Consejo-órgano desconcentrado tuviese, además de esta naturaleza, funciones que no serían propias de ésta y que, en la regulación estatutaria catalana, incluso determinaban la existencia de un doble sistema de recursos para los actos del Consejo en su art.100: en alzada ante el CGPJ cuando no hubieran sido dictados en el ejercicio de competencias de la Comunidad Autónoma (previsión declarada inconstitucional por el TC) y en segundo lugar, el resto de los actos «pueden impugnarse jurisdiccionalmente en los términos establecidos en las leyes».
} 
dents. 1.2. The current statutory reform process and the diversity of models. 2. The Council of Justice in the Statute of Autonomy of Catalonia and its examination by the Constitutional Court. 2.1. Premise: the possibility of collaboration between the Statute and the LOPJ. 2.2. The collaboration between the Statute and the LOPJ in the field of justice in the ruling on the Catalan Statute. 2.3. Elements of the examination by the Constitutional Court on the Council of Justice. 2.3.1. The exclusion of collaboration between laws. 2.3.2. The confusion about the nature of the Council. 2.3.3. The distinction between functions and the reinvention of the body. 2.4. Scenarios after the ruling.

\title{
Resumen
}

En el actual proceso de reformas estatutarias se ha puesto de manifiesto el problema de la relación entre Poder Judicial y modelo de Estado, y los diversos estatutos hasta ahora reformados han incorporado previsiones dirigidas a abordar esta cuestión. El objeto de este trabajo es analizar las relativas a los consejos de justicia, y estudiar asimismo el tratamiento que de esta cuestión ha hecho el Tribunal Constitucional en su sentencia 31/2010, con la consecuencia ya conocida de la declaración de inconstitucionalidad de buena parte de los preceptos alusivos a dicho consejo en el Estatuto de Autonomía de Cataluña. Para ello, y tras analizar brevemente las propuestas existentes antes del inicio de los procesos de reforma estatutaria, se pondrá de manifiesto cómo los estatutos recogen en realidad dos modelos distintos de consejo de justicia, solo uno de los cuales tiene relación realmente con el gobierno del Poder Judicial. En lo relativo al caso catalán y a su examen por el TC, se analizará con carácter previo la noción de colaboración internormativa entre Estatuto y LOPJ, presupuesto de la regulación contenida en el Título III del Estatuto, para concluir que el TC la admite en todos los ámbitos regulados en dicho Título III excepto en el caso del Consejo de Justicia. Asimismo, se indicará cómo la decisión del TC sobre aquél está presidida por una cierta confusión en cuanto a la naturaleza del órgano enjuiciado, y cómo la solución finalmente adoptada, de mantener el órgano pero cambiando totalmente su naturaleza tras la declaración de inconstitucionalidad de buena parte de la regulación del mismo, constituye una solución sorprendente y no exenta de problemas. Finalmente, se identifican las perspectivas de futuro en el ámbito analizado.

\begin{abstract}
In the current statutory reform process has highlighted the problem of the relationship between the Judiciary and the model of State. The re-
\end{abstract}


formed statutes have included rules to settle this issue, and the purpose of this study is to analyze the rules concerning the Councils of Justice, and also consider the treatment of this issue made by the Constitutional Court in its Judgement 31/2010, which declared the unconstitutionality of much precepts alluding to the Council in the Statute of Autonomy of Catalonia. To this end, after briefly reviewing the existing proposals before the start of the statutory reform processes, it will be analysed how the statutes listed in fact two distinct models of Councils of Justice, only one of which actually relates to the government of the Judiciary. After this, regarding the case of Catalonia and its consideration by the Constitutional Court, it will be discussed the notion of collaboration between the Statute and LOPJ, as the basis of the rules contained in Title III of the Statute, to conclude that the Constitutional Court support it at all areas covered in that Title III except in the case of the Council of Justice. It shall also indicate how the decision of the Constitutional Court is also headed by a certain confusion about the nature of the Council of Justice, and how the solution finally adopted, to maintain the body but completely changing its nature, and declaring the unconstitutionality of the main part of the regulation, is a surprising solution and not free of problems. Finally, the work identifies the prospects in the field analysed.

\section{Palabras Clave}

Poder Judicial, Estado autonómico, reforma estatutaria, Consejo de Justicia, CGPJ

\section{Keywords}

Judiciary, Autonomous State, statutory reform, Council of Justice, CGPJ 
